Revista Brasileira de Agricultura Irrigada v.13, nº.6, p. 3773 - 3782, 2019

ISSN 1982-7679 (On-line)

Fortaleza, CE, INOVAGRI - http://www.inovagri.org.br

DOI: $10.7127 /$ rbai.v13n6001162

Protocolo 1162.19 - 04/05/2020 Aprovado em 10/05/2020

\title{
CRESCIMENTO, BIOMASSA E EFICIÊNCIA DE USO DA ÁGUA EM GENÓTIPOS DE PALMA FORRAGEIRA CONSORCIADOS COM PLANTAS DE GLIRICÍDIA, EM RESPOSTAS AO HIDROGEL
}

Francisco Fábio Chagas de Oliveira ${ }^{1}$, Lucio José Vieira Silva ${ }^{1}$, Marcos Vinicius Aquino de Souza ${ }^{1}$, Gleyciane Rodrigues Lins ${ }^{1}$, Alexandre Reuber Almeida da Silva ${ }^{2}$, Raimunda Thaiz Mendes Silva ${ }^{3}$

\section{RESUMO}

Objetivou-se, com o presente trabalho, avaliar o crescimento, a produção e a produtividade de biomassa, bem como a eficiência de utilização da água em dois genótipos de palma forrageira ("Gigante" e "Orelha de elefante"), sob efeitos da presença e da ausência de hidrogel no solo, cultivados em um sistema consorciado com plantas de gliricídia, sob condições naturais de suprimento hídrico, nas condições edafoclimáticas do município de Iguatu, CE. O experimento foi conduzido em um delineamento experimental de blocos ao acaso, no arranjo de parcelas subdivididas, com quatro repetições ( 2 x 4 x 4). Nas parcelas, avaliaram-se os efeitos da presença e da ausência do hidrogel. Nas subparcelas, avaliaram-se os diferentes genótipos de palma forrageira "Gigante" e "Orelha de elefante". Os genótipos de palma forrageira "Gigante" e "Orelha de elefante" exibiram uma resposta diferencial em todas as variáveis de crescimento avaliadas. A espessura dos cladódios foi favorecida pela aplicação do hidrogel, independente do genótipo. O genótipo "Orelha de elefante" possui um maior número de cladódios por planta e uma maior espessura dos cladódios em relação a "Gigante", independente da aplicação do hidrogel. O hidrogel foi capaz de favorecer o comprimento e a largura dos cladódios no genótipo "Orelha de elefante", não alterou o comprimento dos cladódios na palma "Gigante" e comprometeu a largura dos cladódios na palma "Gigante". A partir dos resultados, recomenda-se a utilização do genótipo "Orelha de elefante" associado à adoção de hidrogel no solo.

Palavras-chave: Cultivares; déficit hídrico; Opuntia sp.,

\footnotetext{
${ }^{1}$ Graduandos em Tecnologia em Irrigação e Drenagem, Departamento de Ensino, Instituto Federal de Educação, Ciência e Tecnologia do Ceará (IFCE) - campus Iguatu, Iguatu - CE, Brasil, Rodovia Iguatu/Várzea alegre, km 05, s/n, Vila Cajazeiras, CEP: 63.503-790, e-mail: fabiooliveira199025@gmail.com; lucio2018tid@gmail.com; vini.ifet@gmail.com; gleycianelins15@gmail.com

${ }^{2}$ Professor do Ensino Básico, Técnico e Tecnológico, Departamento de Ensino, Instituto Federal de Educação, Ciência e Tecnologia do Ceará (IFCE) - campus Iguatu, Iguatu - CE, Brasil, Rodovia Iguatu/Várzea alegre, km 05, s/n, Vila Cajazeiras, CEP: 63.503-790, e-mail: alexandre.reuber@ifce.edu.br

${ }^{3}$ Professora do Ensino Básico, Coordenadoria Regional de Desenvolvimento da Educação (CREDE) - Regional Iguatu, Secretaria de Educação (SEDUC - CE), Iguatu - CE, Brasil, Rua 13 de Maio, n. 55, Planalto, CEP: 63.500-000, rthaizmendes@gmail.com
} 


\title{
GROWTH, BIOMASS AND EFFICIENCY OF WATER USE IN FORAGE PALM GENOTYPES CONSORTIATED WITH GLYERICIDE PLANTS, IN RESPONSES TO HYDROGEL
}

\begin{abstract}
The objective of this study was to evaluate the growth, production and productivity of biomass, as well as the efficiency of water use in two genotypes of forage palm ("Gigante" and "Elephant's ear"), under the effects of presence and absence of hydrogel in the soil, grown in a system intercropped with gliricidia plants, under natural water supply conditions, in the edaphoclimatic conditions of the municipality of Iguatu, CE. The experiment was carried out in a randomized block design, in the arrangement of subdivided plots, with four replications $(2 \times 4 \times 4)$. In the plots, the effects of the presence and absence of the hydrogel were evaluated. In the subplots, the different genotypes of forage palm "Gigante" and "Elephant's ear" were evaluated. The genotypes of forage palm "Gigante" and "Elephant ear" showed a differential response in all growth variables evaluated. The thickness of the cladodes was favored by the application of the hydrogel, regardless of the genotype. The "Elephant Ear" genotype has a greater number of cladodes per plant and a greater thickness of the cladodes in relation to "Gigante", regardless of the hydrogel application. The hydrogel was able to favor the length and width of the cladodes in the "Elephant ear" genotype, did not change the length of the cladodes in the "Gigante" palm and compromised the width of the cladodes in the "Gigante" palm. From the results, it is recommended to use the "Elephant ear" genotype associated with the adoption of hydrogel in the soil.
\end{abstract}

Keywords: Cultivars, Opuntia sp., water deficit.

\section{INTRODUÇÃO}

No semiárido nordestino, a irregularidade das precipitações no tempo e no espaço e as temperaturas predominantemente elevadas trazem consequências extremamente negativas para os produtores do setor agropecuário, desafiando-os a buscarem alternativas para fazerem o uso do capital natural para a sobrevivência, capazes de neutralizarem ou mesmo evitarem as consequências da estiagem prolongada (RAMALHO, 2013).

Presume-se que a escolha das espécies vegetais adaptadas às condições locais é um fator que contribui diretamente para o sucesso do projeto agropecuário. Dentre essas espécies, a palma forrageira (Opuntia fícus indica (L.) Mill) tem se tornado uma das fundamentais opções para alimentação dos rebanhos, sendo crescente $\mathrm{o}$ interesse por incrementar áreas cultivadas com essa cultura (BEZERRA et al., 2014).

A palma forrageira aponta-se como uma espécie bem adaptada às condições climáticas do semiárido, em virtude de uma série de mecanismos fisiológicos e metabólicos específicos, capazes de fazerem com que a mesma supere as faltas de chuvas, alcançando produtividades satisfatórias, a partir de um restrito suprimento hídrico, revestindo-a de uma singular eficiência de utilização da água na produção de biomassa (OLIVEIRA et al., 2011).

Entretanto, existe uma expressiva variabilidade genética nas respostas dos genótipos da espécie em questão frente à disponibilidade hídrica, o que determina a necessidade de estudos, visando identificar materiais mais adaptados às características edafoclimáticas locais.

A cultivar de palma forrageira "Gigante" é a mais cultivada na região do semiárido, por apresentar uma maior resistência e tolerância à seca intensas e por deter resistência genética a infestação de cochonilhas de escamas (SANTOS et al., 2010). Paralelamente, a palma forrageira, cultivar "Orelha de Elefante", possui elevada adaptação ao clima quente, tolerância à seca, e apresenta boa aceitação pelos animais (LUCENA et al., 2018). 
Inúmeras são as suposições quanto à baixa exigência hídrica da palma, no que se refere à absorção, aproveitamento e perda de água, especialmente derivadas do Metabolismo Ácido das Crassuláceas, que lhe é inerente (SILVA et al., 2014).

Todavia, estudos têm apontado que o desenvolvimento dessa espécie varia com as oscilações das condições hídricas. Segundo Queiroz et al. (2015), supõe-se que os efeitos benéficos do favorecimento hídrico sob 0 desempenho agronômico da palma forrageira são mais manifestados em regiões caracterizadas por quantitativos pluviométricos demasiadamente baixos, quando comparados as regiões nas quais os valores de precipitações superam os $740 \mathrm{~mm}$, exemplo, tendo em vista que o excesso de água também tende a inibir o desenvolvimento das plantas.

Várias estratégias surgiram para melhorar a disponibilidade de água nos solos do semiárido, tais como o uso de condicionadores químicos, inclusive de polímeros hidrogéis, que podem reter mais eficazmente a água da chuva e disponibilizá-la por períodos mais longos.

Nesse sentido, o uso de condicionadores de solo, tais como o hidrogel, têm apresentado resultados satisfatórios. Trata-se de um polímero hidrofílico, capaz de reduzir as perdas de água por evaporação ou por percolação profunda, mostrando-se como uma opção promissora nos cultivos de plantas em regime de sequeiro. Segundo Ferreira et al. (2014), o hidrogel possui a habilidade de concentrar de
150 a 400 vezes a sua massa seca em água, atenuando os problemas decorrentes da disponibilidade irregular ou deficitária de água no solo.

No entanto, pesquisas sobre aludidos aspectos são escassas, especialmente sob as condições edafoclimáticas do semiárido brasileiro.

Nesse contexto, objetivou-se, com o presente trabalho, avaliar a produção e a produtividade de biomassa e a eficiência de utilização da água em dois genótipos de palma forrageira ("Gigante" e "Orelha de elefante"), sob efeitos da presença e da ausência de hidrogel no solo, cultivados em um sistema consorciado com plantas de gliricídia, sob condições naturais de suprimento hídrico, nas condições edafoclimáticas do município de Iguatu, CE.

\section{MATERIAL E MÉTODOS}

O experimento foi conduzido na área experimental do campus Iguatu do Instituto Federal de Educação, Ciência e Tecnologia do Ceará (IFCE), localizada no município de Iguatu, CE 6 $21^{\prime} 34^{\prime \prime}$ de latitude sul e $39^{\circ} 17^{\prime} 55^{\prime}$ ' de longitude oeste, cujo o clima, segundo Koppen, é do tipo BSW'h' (Semiárido quente), em um solo classificado como Planossolo, cuja caracterização química e física encontram-se apresentadas na Tabela 1, ao longo da estação chuvosa do ano de 2019 (Tabela 2).

Tabela 1. Caracterização química e física do solo da área experimental. Iguatu - CE, $2019^{1}$

\begin{tabular}{|c|c|c|c|c|c|c|c|c|c|c|}
\hline \multirow[t]{2}{*}{ Prof. (m) } & $\mathrm{C}$ & MO & $\mathrm{pH}$ & $\mathrm{P}$ & $\mathrm{K}$ & $\mathrm{Ca}$ & $\mathrm{Mg}$ & $\mathrm{Na}$ & $\mathrm{Al}$ & $\mathrm{H}+\mathrm{Al}$ \\
\hline & \multicolumn{2}{|c|}{$\left(--\mathrm{g} \mathrm{kg}^{-1}--\right)$} & $(-)$ & $\left(\mathrm{mg} \mathrm{d}^{\mathrm{m}-3}\right)$ & \multicolumn{6}{|c|}{ (------------------- $\mathrm{mmol}_{\mathrm{c}} \mathrm{dm}^{-3}$--------------------- } \\
\hline 0,00 & 3,26 & 5,62 & 5,8 & 4 & 3,36 & 34,4 & 14,7 & 0,42 & N.D. & 11,6 \\
\hline 0,2 & 2,63 & 4,54 & 5,4 & 10 & 2,93 & 26,6 & 8,9 & 0,63 & 0,5 & 14,9 \\
\hline \multirow{2}{*}{ Prof. (m) } & SB & CTC & $\mathrm{V}$ & PST & $\mathrm{m}$ & $\mathrm{CE}$ & $\mathrm{D}$ & $\mathrm{D}_{\mathrm{S}}$ & \multirow{2}{*}{\multicolumn{2}{|c|}{$\begin{array}{c}\text { Classificação } \\
\text { textural }\end{array}$}} \\
\hline & \multicolumn{2}{|c|}{$\left(\mathrm{mmol}_{\mathrm{c}} \mathrm{dm}^{-3}\right)$} & \multicolumn{3}{|c|}{ (---------- \% ----------) } & $\left(\mathrm{dS} \mathrm{m} \mathrm{m}^{-1}\right)$ & \multicolumn{2}{|c|}{$\left(\mathrm{g} \mathrm{cm}^{-3}\right)$} & & \\
\hline $0,00-$ & 52,9 & 64,5 & 82 & 1 & 0 & 0,34 & 1,39 & 2,76 & \multicolumn{2}{|c|}{ Franco - Argilo } \\
\hline $0,20-0,40$ & 39,1 & 54,0 & 72 & 1 & 1 & 0,31 & 1,32 & 2,72 & & enosa \\
\hline
\end{tabular}

${ }^{1}$ Profundidade (Prof); Extrator de P, Na e K - Mehlich; Ca, Mg e Al - KCl; H + Al - Acetato de cálcio; pH - água (1:2,5); Matéria Orgânica (M.O); Soma de Bases (SB); Capacidade de troca de cátions (CTC); Porcentagem de saturação de bases (V); Percentagem de sódio trocável (CTC), Percentagem de saturação por alumínio (m), Condutividade elétrica do extrato de saturação (CE), Densidade do solo (D) e densidade das partículas ( $\mathrm{D}_{\mathrm{S}}$ ). 
Tabela 2. Precipitações acumuladas, ao longo do período experimental Iguatu - CE, $2019^{2}$

\begin{tabular}{lllllll}
\hline \multirow{2}{*}{ Espécies vegetais } & \multicolumn{7}{l}{ Precipitação $(\mathrm{mm}$ período } \\
& Fevereiro & Março & Abril & Maio & Junho & Total acumulado \\
\hline Gliricídia & 14,00 & 212,00 & 286,00 & 69,00 & 41,00 & 622,00 \\
Genótipos de Palma & 0,00 & 7,00 & 286,00 & 69,00 & 41,00 & 403,00
\end{tabular}

${ }^{2}$ Valores registrados em uma estação agrometeorológica convencional, instalada nas imediações da área experimental.

O experimento foi conduzido sob delineamento experimental de blocos ao acaso, no arranjo de parcelas subdivididas, com quatro repetições $(2 \times 4)$. Nas parcelas, avaliaram-se os efeitos da presença e da ausência do hidrogel.

Nas subparcelas, avaliaram-se os diferentes genótipos de palma forrageira "Gigante" e "Orelha de elefante", oriundos de uma empresa especializada, propagados via cultura de tecidos, as quais foram transplantadas nas entre linhas das plantas de gliricídia.

As plantas de gliricídia foram transplantadas para a área experimental em meados de fevereiro de 2019, no espaçamento de $4 \mathrm{~m}$ entre fileiras e de $4 \mathrm{~m}$ entre plantas dentro da fileira, enquanto as plantas de milheto, espécie integrante do sistema consorciado, foram transplantadas nas entrelinhas, obedecendo ao espaçamento de 2,0 $\mathrm{m}$ entre fileiras de plantas e de $1,0 \mathrm{~m}$ entre plantas na fileira. Nas parcelas submetidas a aplicação de hidrogel, utilizou-se o produto comercial FORTHGEL $^{\circledR}$, na dosagem para hidratação de $4 \mathrm{~g} \mathrm{~L}^{-1}$, conforme as orientações de preparo da solução e de aplicação disponibilizadas pelo próprio fabricante do produto comercial.

Aos 120 dias após o transplantio dos genótipos de palma, em pleno estádio vegetativo do crescimento vegetativo avaliaram-se às seguintes variáveis de crescimento: número de cladódios por planta, através de contagem direta; espessura dos cladódios, determinada com o auxílio de um paquímetro digital; comprimento cladódios e largura dos cladódios, determinados com o auxílio de uma fita métrica.

Nessa mesma ocasião, avaliaram-se, também produção de biomassa fresca por planta (BP); a produtividade de biomassa fresca
(PROD) e a eficiência de uso da água na produção de biomassa fresca (EUA). A estimativa da biomassa fresca por planta no campo (BP), no campo, foi determinada de forma não destrutiva, segundo metodologia proposta por Menezes et al. (2005).

Para tanto, estimou-se a biomassa fresca média dos cladódios (BFC), utilizando-se da equação 1, abaixo apresentada:

$\mathrm{BFC}=\mathrm{C} \times \mathrm{L} \times \mathrm{E} \times 0,535$

Em que: FC - biomassa fresca do cladódio, em g; C - Comprimento médio dos cladódios, em cm; L - Largura média dos cladódios, em cm; E - Espessura média dos cladódios, em cm; 0,535 - Fator resultante da multiplicação do fator de correção da área $(0,883)$ pelo peso específico corrigido $\left(0,772 \mathrm{~g} \mathrm{~cm}^{-3}\right)$, pelo valor de $3,14 \mathrm{e}$ por $1 / 4$, provenientes do cálculo da área da elipse, em $\mathrm{g} \mathrm{cm}^{-3}$.

Posteriormente, para a obtenção da produção de biomassa fresca por planta (BP), multiplicou-se a biomassa fresca média dos cladódios (BFC) pelo número médio de cladódios por planta.

Sequencialmente, para a obtenção da produtividade de biomassa fresca (PROD) em $\mathrm{Kg} \mathrm{ha}^{-1}$, multiplicou-se a produção de biomassa fresca por planta (BP) pelo número de plantas por hectare (SILVA, 2017).

Finalmente, por meio da relação entre a produtividade de biomassa fresca (PROD) em $\mathrm{Kg} \mathrm{ha}{ }^{-1}$ e a precipitação incidida durante a estação de cultivo, estimou-se a eficiência de uso da água na produção de biomassa fresca (EUA).

Os dados obtidos foram submetidos à análise da variância pelo teste $\mathrm{F}$ a $1 \%$ e $5 \%$ de probabilidade. Quando verificado efeito significativo, as médias foram comparadas pelo teste de Tukey em nível de $5 \%$ de 
probabilidade, utilizando-se o programa computacional para assistência estatística ASSISTAT 7.7 pt (UFCG).

\section{RESULTADOS E DISCUSSÃO}

Os genótipos de palma forrageira "Gigante" e "Orelha de elefante" exibiram uma resposta significativamente diferente $(p<0,05)$ em todas as variáveis de crescimento avaliadas.
Já as variáveis espessura dos cladódios, o comprimento dos cladódios e o número de cladódio mostraram-se ser influenciados estaticamente $(\mathrm{p}<0,05)$ pela presença do hidrogel.

Enquanto estatisticamente significativas frente as significativas frente aos efeitos das interações entre os fatores em estudo foram detectadas nas variáveis comprimento e largura dos cladódios (Tabela 3).

Tabela 3. Resumo das análises das variâncias para os dados médios de número de cladódios por planta (NCP), espessura dos cladódios (EC), comprimento dos cladódios (CC) e largura dos cladódios (LC) dos genótipos de palma forrageira "Gigante" e "Orelha de elefante" em respostas ao hidrogel, cultivados em sistema consorciado com plantas de gliricídia. Iguatu - CE, $2019^{3}$

\begin{tabular}{llllll}
\hline F.V. & G.L. & NCP & EC & CC & LC \\
\hline Blocos & 3 & $0,50^{\text {ns }}$ & $0,25^{\text {ns }}$ & $3,53^{\text {ns }}$ & $2.99^{\text {ns }}$ \\
Genótipos (G) & 1 & $2,25^{*}$ & $5,38^{*}$ & $416,12^{* *}$ & $129,13^{*}$ \\
Resíduo - G & 3 & 0,08 & 0,40 & 0,49 & 9,88 \\
\hline Parcelas & 7 & $(-)$ & $(-)$ & $(-)$ & $(-)$ \\
\hline Hidrogel (H) & 1 & $0,25^{\text {ns }}$ & $7,27^{*}$ & $115,06^{* *}$ & $108,28^{* *}$ \\
Int. G x H & 1 & $1,00^{\text {ns }}$ & $3,01^{\text {ns }}$ & $154,56^{* *}$ & $359.14^{* *}$ \\
Resíduo - H & 6 & 0,29 & 0,71 & 0,97 & 3,98 \\
\hline Total & 15 & $(-)$ & $(-)$ & $(-)$ & $(-)$ \\
\hline C.V. - G (\%) & & 12,83 & 8,22 & 3,43 & 10,48 \\
C.V. - H (\%) & & 24,00 & 10,68 & 4,82 & 6,65 \\
\hline
\end{tabular}

${ }^{3}$ Fontes de variação (F.V.); Graus de liberdade (G.L.); Coeficiente de variação (C.V.); Não significativo ( ${ }^{\text {ns }}$ ), Significativo a $1 \%\left(^{* *}\right)$ e $5 \%\left(^{*}\right)$ de significância, pelo teste $\mathrm{F}$.

Constata-se que o genótipo "Orelha de elefante" apresentou valores superiores para as variáveis número de cladódios por planta e espessura dos cladódios, os quais, diferiram estatisticamente daqueles constatados para o genótipo "Gigante", com valores médios superiores em aproximadamente 40,10 e $16,15 \%$; para as aludidas variáveis, respectivamente, quando comparados entre si (Tabela 4).

Tabela 4. Número de cladódios por planta (NCP, unidades) e espessura dos cladódios (EC, mm) dos genótipos de palma forrageira "Gigante" e "Orelha de elefante", cultivados em sistema consorciado com plantas de gliricídia. Iguatu - CE, $2019^{3}$

\begin{tabular}{lll}
\hline Genótipos & NCP (unidades) & EC $(\mathrm{mm})$ \\
\hline Palma "Gigante" & $1,87 \mathrm{~b}$ & $7,18 \mathrm{~b}$ \\
Palma "Orelha de elefante" & $2,62 \mathrm{a}$ & $8,34 \mathrm{a}$
\end{tabular}

${ }^{4}$ Médias seguidas por letras iguais minúsculas nas colunas não diferem estatisticamente entre si pelo teste de Tukey $(\mathrm{p}=$ $0,05)$.

Mesmo diante das detecções das diferenças estatisticamente significativas para as variáveis número de cladódios por planta e espessura dos cladódios, infere-se que as amplitudes de variações entre os genótipos avaliados, para essas variáveis, podem ser consideradas relativamente pequenas, o que pode estar assoado ao fato de ambos os 
genótipos pertencerem ao mesmo gênero (Opuntia spp.), caracterizados, no geral, por apresentarem menor quantidade de cladódios e de menores espessuras, quando comparadas às do gênero Nopalea sp., conforme reportam Cavalcante et al. (2014). Quanto à espessura dos cladódios, verifica-se que, independente do genótipo avaliado, em média, a presença do hidrogel favoreceu o incremento dessa variável, com valores estatisticamente superiores, que, por sua vez, superam em aproximadamente 19\%, quando comparados aos obtidos na ausência do hidrogel (Tabela 5).

Tabela 5. Espessura dos cladódios dos genótipos de palma forrageira "Gigante" e "Orelha de elefante" em respostas ao hidrogel, cultivados em sistema consorciado com plantas de gliricídia. Iguatu - CE, $2019^{5}$

\begin{tabular}{lll}
\hline \multirow{2}{*}{$\mathrm{EC}(\mathrm{mm})$} & Sem hidrogel & Com hidrogel \\
\cline { 2 - 3 } & $7,08 \mathrm{~b}$ & $8,43 \mathrm{a}$ \\
\hline
\end{tabular}

${ }^{5}$ Médias seguidas por letras iguais minúsculas nas linhas não diferem estatisticamente entre si pelo teste de Tukey $(\mathrm{p}=$ $0,05)$.

O incremento da espessura dos cladódios em resposta ao hidrogel, independentemente do genótipo avaliado, pode ser decorrente dos prováveis benefícios que o hidrogel acarretou no que tange à disponibilidade da água no solo. Fato que, possivelmente, poderá estar associado ao maior grau de turgescência dos cladódios (FERRAZ et al., 2018), o que leva a supor que a espessura dos cladódios parece ser mais sensível às variações de umidade do solo que o número de cladódios por planta. Fato também observado por Sales et al. (2016), que observaram variações na espessura dos cladódios da cultivar Miúda e atribuíram esses efeitos aos pulsos de precipitação pluvial.

O desdobramento da interação significativa para a variável comprimento dos cladódios denotou que a presença do hidrogel apenas promoveu variações estatisticamente significativas $(p<0,05)$ no genótipo "Orelha de elefante", onde o condicionador de solo foi capaz de conferir incrementos médios percentuais de aproximadamente $58 \%$ (Tabela 6).

Tabela 6. Comprimento dos cladódios (CC, em centímetros - cm) e largura dos cladódios (LC, em milímetros - mm) dos genótipos de palma forrageira "Gigante" e "Orelha de elefante" em respostas ao hidrogel, cultivados em sistema consorciado com plantas de gliricídia. Iguatu - CE, 2019

\begin{tabular}{lllll}
\hline \multirow{2}{*}{ Genótipos } & \multicolumn{3}{c}{ LC $(\mathrm{cm})$} & \multicolumn{3}{c}{)} \\
\cline { 2 - 5 } & Sem hidrogel & Com hidrogel & Sem hidrogel & Com hidrogel \\
\hline Palma "Gigante" & $15,85 \mathrm{bA}$ & $14,99 \mathrm{bA}$ & $29,30 \mathrm{aA}$ & $25,02 \mathrm{bB}$ \\
Palma "Orelha de elefante" & $19,83 \mathrm{aB}$ & $31,41 \mathrm{aA}$ & $25,50 \mathrm{aB}$ & $40,18 \mathrm{aA}$ \\
\hline
\end{tabular}

${ }^{6}$ Médias seguidas por letras iguais maiúsculas nas linhas e minúsculas nas colunas não diferem estatisticamente entre si pelo teste de Tukey $(\mathrm{p}=0,05)$.

Nesse mesmo genótipo, foram verificados os maiores valores para essa variável, superiores estatisticamente $(\mathrm{p}<0,05)$ aos encontrados para o genótipo "Gigante", sendo verificados incrementos percentuais da ordem de aproximadamente 25 e $109 \%$ para as plantas cultivadas na ausência e na presença de hidrogel, respectivamente. Já no que se relaciona à largura dos cladódios, verifica-se que na ausência do hidrogel, ambos os genótipos exibiram valores estatisticamente similares $(p>0,05)$. A presença do hidrogel proporcionou valores significativamente maiores $(p<0,050)$ de Largura dos Cladódios no genótipo "Orelha de elefante", ou seja, incremento percentual de aproximadamente $60 \%$, quando comparado com o valor obtido no genótipo "Gigante".

A presença do hidrogel foi capaz de favorecer o incremento da largura dos cladódios apenas do genótipo "Orelha de elefante", com valores estaticamente 
superiores, em aproximadamente 57\%, ao passo que o hidrogel reduziu em aproximadamente $17 \%$ o valor médio da referida variável, para o genótipo "Gigante", o qual, exibiu valores estaticamente superiores $(\mathrm{p}<0,05)$, quando cultivados na ausência do hidrogel (Tabela 6).

Em síntese, pode-se considerar que as variáveis de crescimento comprimento e largura dos cladódios guardam estreita relação com as variáveis condicionadoras da produção, uma vez que para que a espécie vegetal eleve o seu potencial produtivo, é imperativo que ocorra o processo de expansão dos tecidos vegetais, que pode ser detectado pelo acréscimo na espessura dos cladódios, bem como pela ampliação do número de cladódios, que também influenciam diretamente no comprimento e na largura dos mesmos, o que leva a supor que essas variáveis morfológicas e produtivas estão reciprocamente interligadas (SOUZA et al., 2018). Segundo Pinheiro et al. (2014), adicionalmente, além da produção de biomassa na palma forrageira ser dependente das correlações entre os comentes de crescimento, é importante destacar que a espécie é também extremamente dependente das condições edafoclimáticas vigentes, em especial, aquilo que se relaciona à disponibilidade hídrica do solo.

Para o aludido autor, a definição da amplitude da resposta da cultura da palma às situações distintas depende da interação direta entre os efeitos ambientais e genéticos, o que é capaz de explicar as respostas diferenciadas das variáveis aos fatores em estudo.

Foram verificadas diferenças estatisticamente significativas para os efeitos principais genótipos e hidrogel e para a interação genótipos $\mathrm{x}$ hidrogel, pelo teste $\mathrm{F}$, para as variáveis produção de biomassa fresca por planta (BP), produtividade de biomassa fresca (PROD) e eficiência de uso da água na produção de biomassa fresca (EUA, conforme o exposto na Tabela 7.

Tabela 7. Resumo das análises das variâncias para os dados de produção de biomassa fresca por planta (BP), produtividade de biomassa fresca (PROD) e eficiência de uso da água na produção de biomassa fresca (EUA) dos genótipos dos genótipos de palma forrageira "Gigante" e "Orelha de elefante" em respostas ao hidrogel, cultivados em sistema consorciado com plantas de gliricídia. Iguatu - CE, $2019^{7}$

\begin{tabular}{lllll}
\hline F.V. & G.L. & BP & PROD & EUA \\
\hline Blocos & 3 & $1.375,84^{\mathrm{ns}}$ & $34.396,05^{\mathrm{ns}}$ & $0,21^{\mathrm{ns}}$ \\
Genótipos (G) & 1 & $28.218,06^{*}$ & $705.451,37^{*}$ & $4,34^{*}$ \\
Resíduo - G & 3 & $1.135,91$ & 28397,82 & 0,17 \\
\hline Parcelas & 7 & $(-)$ & $(-)$ & $(-)$ \\
\hline Hidrogel (H) & 1 & $12.940,96^{*}$ & $323.524,07^{*}$ & $1,99^{*}$ \\
Int. G x H & 1 & $21.630,88^{* *}$ & $540.772,09^{* *}$ & $3,32^{* *}$ \\
Resíduo - H & 6 & $1.003,59$ & $25.089,72$ & 3,32 \\
\hline Total & 15 & $(-)$ & $(-)$ & $(-)$ \\
\hline C.V. - G (\%) & & 46,60 & 46,60 & 46,60 \\
C.V. - H (\%) & & 43,80 & 43,80 & 43,80 \\
\hline
\end{tabular}

${ }^{7}$ Fontes de variação (F.V.); Graus de liberdade (G.L.); Coeficiente de variação (C.V.); Não significativo $\left({ }^{\text {ns }}\right)$, Significativo a $1 \%\left(^{* *}\right)$ e $5 \%\left(^{*}\right)$ de probabilidade, pelo teste $\mathrm{F}$.

A aplicação de hidrogel ao solo não foi capaz de promover variações estatisticamente significativas nas variáveis analisadas no genótipo "Gigante". Todavia, o mesmo foi capaz de potencializar a expressão de todas as variáveis produtivas analisadas no genótipo
"Orelha de elefante", resultando em incrementos médios da ordem de $266 \%$ quando equiparados aos valores obtidos para o genótipo em questão, cultivado na ausência de hidrogel (Tabela 8). 
Tabela 8. Biomassa fresca por planta $\left(\mathrm{BP}, \mathrm{g}\right.$ planta $\left.{ }^{-1}\right)$, produtividade de biomassa fresca (PROD, $\mathrm{kg}$ $\mathrm{ha}^{-1}$ ) e eficiência de uso da água na produção de biomassa fresca (EUA, $\mathrm{kg} \mathrm{ha}^{-1} \mathrm{~mm}^{-1}$ ) dos genótipos dos genótipos de palma forrageira "Gigante" e "Orelha de elefante" em respostas ao hidrogel, cultivados em sistema consorciado com plantas de gliricídia. Iguatu - CE, $2019^{8}$

\begin{tabular}{lllllll}
\hline \multirow{2}{*}{ Genótipos } & \multicolumn{2}{l}{$\mathrm{BP}\left(\mathrm{g}\right.$ planta $\left.{ }^{-1}\right)$} & PROD $\left(\mathrm{kg} \mathrm{ha}^{-1}\right)$ & \multicolumn{2}{l}{ EUA $\left(\mathrm{kg} \mathrm{ha}^{-1} \mathrm{~mm}^{-1}\right)$} \\
\cline { 2 - 7 } & $\begin{array}{l}\text { Sem } \\
\text { hidrogel }\end{array}$ & $\begin{array}{l}\text { Com } \\
\text { hidrogel }\end{array}$ & $\begin{array}{l}\text { Sem } \\
\text { hidrogel }\end{array}$ & $\begin{array}{l}\text { Com } \\
\text { hidrogel }\end{array}$ & $\begin{array}{l}\text { Sem } \\
\text { hidrogel }\end{array}$ & $\begin{array}{l}\text { Com } \\
\text { hidrogel }\end{array}$ \\
\hline $\begin{array}{l}\text { Palma "Gigante" } \\
\text { Palma "Orelha } \\
\text { de elefante" }\end{array}$ & $38,65 \mathrm{aA}$ & $21,99 \mathrm{bA}$ & $193,27 \mathrm{aA}$ & $109,98 \mathrm{bA}$ & $0,47 \mathrm{aA}$ & $0,27 \mathrm{bA}$ \\
& $49,10 \mathrm{aB}$ & $179,52 \mathrm{aA}$ & $245,54 \mathrm{aB}$ & $897,62 \mathrm{aA}$ & $0,60 \mathrm{aB}$ & $2,22 \mathrm{aA}$ \\
\hline
\end{tabular}

${ }^{8}$ Médias seguidas por letras iguais maiúsculas nas linhas e minúsculas nas colunas não diferem estatisticamente entre si pelo teste de Tukey $(\mathrm{p}=0,05)$.

Embora sem a constatação de variação estatisticamente significativa, comprova-se, ainda, a tendência de uma redução percentual média da ordem de $75 \%$, como consequência da presença do hidrogel, no genótipo "Gigante", em todas as variáveis analisadas, o que leva a supor que nas condições nas quais a presente pesquisa foi conduzia o mesmo possuiu um requerimento hídrico inferior, quando comparado com o genótipo "Orelha de elefante", tendo em vista que o provável favorecimento hídrico, proporcionado pelo hidrogel, mostrou-se aparentemente deletério nas variáveis produtivas analisadas (Tabela 8).

Tais resultados, divergem dos obtidos por Campos (2018), ao estimarem que durante 365 dias de cultivo, as cultivares de palma forrageira apresentaram Orelha de elefante e Gigante tiveram, em média, uma evapotranspiração real acumulada média de 42,77 e 264,$7 ; \quad 373,2 \mathrm{~mm} \mathrm{ano}^{-1}$, respectivamente. Observa-se, ainda, que, os genótipos avaliados exibiram respostas estatisticamente similares na ausência do hidrogel, quando equiparados entre si, ao passo que, na presença do hidrogel, o genótipo "Orelha de elefante" foi capaz de exibir valores estatisticamente superiores, em todas as variáveis analisadas (Tabela 8). Resultados similares aos obtidos para o genótipo "Orelha de elefante" quanto aos efeitos do hidrogel foram também obtidos por Nascimento et al. (2020), ao trabalharem com o mesmo genótipo, onde averiguaram que aos 12 meses apresentou um maior rendimento produtivo de biomassa fresca no tratamento que recebeu o hidrogel em relação à testemunha (sem hidrogel).
Segundo os autores supracitados, a quantidade de hidrogel aplicada no referido estudo, possivelmente, não foi suficientemente capaz de resultar em rendimentos produtivos mais significativos. Nesse sentido, os autores propõem que novas pesquisas sejam realizadas em diferentes condições de solos e com dosagem do hidrogel superior ao preconizado pelos fabricantes, visando melhor elucida as relações e subsidiar a tomada de decisão por parte dos produtores rurais. Especialmente, em cultivos de sequeiro.

\section{CONCLUSÕES}

Visando otimizar o crescimento, o desempenho produtivo e a eficiência de utilização da água pela cultura da palma forrageira cultivada em sequeiro, nas condições edafoclimáticas do semiárido nordestino, recomenda-se a utilização do genótipo "Orelha de elefante" associado à adoção de hidrogel no solo.

\section{REFERÊNCIAS BIBLIOGRÁFICAS}

BEZERRA, B. G.; ARAÚJO, J. S.; PEREIRA, D. D.; LAURENTINO, G. Q.; SILVA, L. L. da. Zoneamento agroclimático da palma forrageira (Opuntia sp.) para o estado da Paraíba. Revista Brasileira de Engenharia Agrícola e Ambiental, v. 18 , n. $7, \quad$ p. $755-761,2014$. http:// dx.doi.org/10.1590/

S1415-43662014000700013. 
CAMPOS, A. R. F. Manejo de irrigação na palma forrageira: definição de critérios com base no potencial matricial da água no solo. 2018. 102 f. Tese (Doutorado em Engenharia Agrícola) - Universidade Federal do Recôncavo da Bahia, Cruz das Almas.

CAVALCANTE, L. A. D.; SANTOS, G. R. de A.; SILVA, F., L. M. da; LARA, J.; SILVA, M. A. da. Respostas de genótipos de palma forrageira a diferentes densidades de cultivo. Pesquisa Agropecuária Tropical, v. 44, n. 4, p. 424-433, 2014. https://doi.org/10.1590/S198340632014000400010.

FERRAZ, A. P. F. . Avaliação de clones de palma forrageira no Agreste e Sertão de Pernambuco. 2018. 148 f. Tese (Doutorado em Zootecnia) - Universidade Federal Rural de Pernambuco, Recife.

FERREIRA, E. A.; SILVA, V. A.; SILVA, E. A.; SILVEIRA, H. de R. O. Eficiência do hidrogel e respostas fisiológicas de mudas de cultivares apirênicas de citros sob défice hídrico. Pesquisa Agropecuária Tropical, v. 44, n. 2, p. 158-165, 2014. https://doi.org/10.1590/S1983-

40632014000200009.

LUCENA, L. R. R. de; LEITE, M. L. de M. V.; SIMÕES, V. J. L. P.; SIMÕES, V. J. L. P.; ALMEIDA, M. C. R. de. Área de cladódio da palma Opuntia stricta utilizando dimensões lineares. Agrarian Academy, v. 5, n. 9; p. 4655, $2018 . \quad$ https://doi: 10.18677/agrarian_academy_2018a5.

MENEZES, R. S. C.; SIMÕES D. A.; SAMPAIO, E. V. S. B. A palma do Nordeste do Brasil: conhecimento atual e novas perspectivas de uso. 1 ed. Recife: Editora Universitária da UFPE, 2005. 258 p.

NASCIMENTO, S. M. do; AGUIAR, E. M. de; LIMA, G. F. da C.; NOVAES, L. P.; COSTA, P. R. da. Aspectos gerais da palma forrageira e alternativas de manejo: uma associação do hidrogel agrícola e da adubação foliar. Nutritime Revista Eletrônica, v. 17, n. 2, p. 8681-8698, 2020. https://www.nutritime.com.br/site/wpcontent/uploads/2020/03/Artigo-512-2.pdf

OLIVEIRA, A. S. C.; CAVALCANTE FILHO, F. N.; RANGEL, A. H. do N.; LOPES, K. B. de P. A palma forrageira: alternativa para o semi-árido. Revista Verde, v. 6, n. 3, p. 4958 ,

2011. https://www.gvaa.com.br/revista/index.php/R VADS/article/viewFile/505/683.

PINHEIRO, K. M.; SILVA, T. G. F.; CARVALHO, H. F. S.; SANTOS, J. E. O.; MORAIS, J. E. F.; ZOLNIER, S.; SANTOS, D. C. Correlações do índice de área do cladódio com características morfogênicas e produtivas da palma forrageira. Pesquisa Agropecuária Brasileira, v. 49, n. 12, p. 939-947, 2014. http://dx.doi.org/10.1590/S0100-

204X2014001200004.

QUEIROZ, M. G. de; SILVA, T. G. F. da; ZOLNIER, S.; SILVA, S. M. S. e; LIMA, L. R.; ALVES, J. de O. Características morfofisiológicas e produtividade da palma forrageira em diferentes lâminas de irrigação. Revista Brasileira de Engenharia Agrícola e Ambiental, v. 19, n. 10, p. 931 938, 2015. https://doi.org/10.1590/18071929/agriambi.v19n10p931-938.

RAMALHO, M. F. de J. L. A fragilidade ambiental do Nordeste brasileiro: o clima semiárido e as imprevisões das grandes estiagens. Sociedade e Território, v. 25, n. 2 (edição especial), p. 104-115, 2013. https://periodicos.ufrn.br/sociedadeeterritorio/ article/view/3629/2896.

SALES, A. T.; LEITE, M. L. M. V.; ANDRADE, $\quad$ A. P. Adaptación de cultivares de nopal forrajero al semiárido estado de Paraíba, Brasil. Agronomía Mesoamericana, v. 27, n. $1, \quad$ p. $151-157, \quad 2016$. http://dx.doi.org/10.15517/am.v27i1.21894. 
SANTOS, M. V. F.; LIRA, M. A.; DUBEUX JÚNIOR; FERREIRA, M. A.; CUNHA, M. V. Palma forrageira. In: FONSECA, D. M.; MARTUSCELlO, J. A. (Eds.). Plantas forrageiras. 1 ed. Viçosa: Ed. UFV, 2010. p.459-493.

SILVA, L. M. da; FAGUNDES, J. L.; VIEGAS, P. A. A.; MUNIZ, E. N.; RANGEL, J. H. de A.; MOREIRA, A. L.; BACKES, A. A. Produtividade da palma forrageira cultivada em diferentes densidades de plantio. Ciência Rural, v. 44, n. 11, p. 2064-2071, 2014. http://dx.doi.org/10.1590/0103-

8478cr20131305.

SILVA, P. F. da. Crescimento e produtividade de palma forrageira sob diferentes lâminas de irrigação e adubação nitrogenada. 2017. 79 f. Tese (Doutorado em Engenharia Agrícola) - Universidade Federal de Campina Grande, Campina Grande.

SOUZA, J. T. A; RAMOS, J. P. F.; MACEDO, A. J. S.; VIANA, J. A.; CARTAXO, F. Q.; ORESCA, D.; OLIVEIRA, F. G. Crescimento e produtividade de genótipos de palma forrageira no Semiárido Paraibano. Tecnologia \& Ciência Agropecuária, v. 12, n. 3, p. 37-42, 2018.

http://revistatca.pb.gov.br/edicoes/volume-122018/volume-12-n-3-2018/06-ce-0418-04rendimento-forrageiro-e-crescimento-degenotipos-de-palma-forrageira.pdf 